Creating a Financially Feasible High-Performance Metropolitan Transportation System. Author(s): Patrick DeCorla-Souza

Source: Journal of the Transportation Research Forum, Vol. 49, No. 3 (Fall 2010), pp. 21-38

Published by: Transportation Research Forum

Stable URL: http://www.trforum.org/journal

The Transportation Research Forum, founded in 1958, is an independent, nonprofit organization of transportation professionals who conduct, use, and benefit from research. Its purpose is to provide an impartial meeting ground for carriers, shippers, government officials, consultants, university researchers, suppliers, and others seeking exchange of information and ideas related to both passenger and freight transportation. More information on the Transportation Research Forum can be found on the Web at www.trforum.org. 


\title{
Creating a Financially Feasible High-Performance Metropolitan Transportation System
}

\author{
by Patrick DeCorla-Souza
}

This paper assesses a strategy to alleviate recurring congestion on metropolitan highway systems by adding "dynamic" capacity during peak periods, using shoulders as travel lanes, along with variable peak-period user charges levied on all lanes, to manage demand and pay for the capacity improvements and complementary multimodal investments. It presents an analysis of the traffic, delay, fuel consumption, CO2 emissions, and cost and revenue impacts. The paper then discusses various technical and public acceptance issues with regard to the concept, and how these issues might be addressed.

\section{INTRODUCTION}

\section{Background}

Major metropolitan areas in the U.S. are facing increasing levels of highway congestion, but it is extremely expensive to widen highways in urban areas, and environmental and social constraints limit the ability to expand the highway footprint. The normal cost of construction to add a lane on an urban freeway is estimated at about $\$ 13.4$ million per lane mile by the Federal Highway Administration (2007). Weekday peak period use of a lane addition amounts to about 10,000 vehicles per weekday. As shown in Table 1, the cost per lane mile translates to a cost of about $\$ 7.00$ for a 20-mile trip made on an added urban freeway lane during peak periods.

On the other hand, fuel taxes generated from a 20-mile trip amount to a total of only about 40 cents, calculated based on fuel taxes averaging 40 cents per gallon and an average vehicle fuel efficiency rating of $20 \mathrm{mpg}$. The gap between user-based taxes and cost for a new lane is even higher for high cost urban freeways (see Table 1). Moreover, if new highway capacity is provided for use free of charge, it will continue to encourage low-density land use patterns and increased auto dependence, leading to a return to congestion.

This paper assesses a new financially feasible approach to address metropolitan mobility and access issues that involves congestion pricing with complementary multimodal strategies. Congestion pricing involves the imposition of variable tolls to manage demand during peak periods. By increasing the cost of travel perceived by commuters, it can reduce congestion and provide the revenue needed to make multimodal transportation infrastructure improvements.

\section{Review of the Literature and State of the Practice}

Congestion pricing has been discussed in the economics literature for over 150 years, beginning with the work of Dupuit (1844), Pigou (1920), and Knight (1924). During the 1960s, there was a revitalization of interest with the work of Walters (1961), the Smeed Report (Ministry of Transport 1964), and Vickrey (1968).

This early work led to the earliest implementation of congestion pricing in the form of an Area Licensing Scheme in the Singapore Central Business District (CBD) in 1975. This was followed by implementation of cordon-based pricing or "toll rings" in several Norwegian cities in the late 1980s and 1990s. In the 2000s electronic toll collection (ETC) facilitated the implementation of congestion pricing in the form of a charge to drive within Central London. Stockholm has implemented cordonbased charges to drive into and out of the central city. Over the past 15 years, congestion pricing 
Table 1: Costs for Highway Construction in Major Urban Areas

\begin{tabular}{lrr}
\hline & Normal Cost & High Cost \\
\hline Construction cost per lane mile* & $\$ 13,400,000$ & $\$ 55,900,000$ \\
Daily traffic volume in peak periods & 10,000 & 10,000 \\
Construction cost per vehicle per mile & $\$ 1,340$ & $\$ 5,590$ \\
Construction cost for 20-mile round trip & $\$ 26,800$ & $\$ 111,800$ \\
Annualized construction cost for 20-mile round trip** & $\$ 1,742$ & $\$ 7,267$ \\
Cost for 20-mile round trip per working day & $\$ 6.97$ & $\$ 29.07$ \\
Gas tax paid for a 20-mile round trip & $\$ 0.40$ & $\$ 0.40$ \\
\hline
\end{tabular}

* Source: FHWA 2007 (2006 dollars)

** Annualization factor 0.065 assuming a $5.25 \%$ discount rate and 30 years

has also been implemented on some existing toll facilities in France and the United States, and on a few existing or new lanes on freeways in the United States, known as express toll lanes or HighOccupancy Toll (HOT) lanes. HOT lanes are High-Occupancy Vehicle (HOV) lanes which may be used by non-HOVs with payment of a toll. With such priced lanes a two-class service is offered, for which users have a choice: a standard or "free" untolled service that may incur delay, and a premium or "express" service that offers higher speed for the price of a toll.

As Lee (2009) has demonstrated, however, in many situations single-class unpriced service may be better than two-class service with one class priced. Lee points out that splitting a facility into two classes reduces the effective capacity and total vehicle throughput of a facility. He finds that the justification for more than one class of service requires that the preferences (value of time) among users be very heterogeneous, but peak period travelers are probably more homogeneous than average because they are employed and have higher incomes. He concludes that the only way a priced lane can be superior to a fully-priced single-class facility is if prices are charged on both classes of lane, standard and premium. Nevertheless, HOT and express toll lane projects with adjacent unpriced lanes continue to be implemented in the United States, and 62 more are in various stages of planning, development, and implementation (FHWA 2009). They are publicly acceptable because generally no one is made worse off, since no existing general purpose lanes are priced.

Although a fully-priced single-class facility might be economically superior, as Lee (2009) suggests, it has encountered obstacles to implementation due to public acceptance issues. This is understandable, because both the tolled and the tolled off (i.e., those who avoid using the road during the priced periods due to the new charges) are shown to be worse off under a constant value of time assumption (Hau 2005). Those who are tolled off are "forced" into less desirable modes, routes, or times of day. Those who are tolled are worse off on average because, in order to reduce demand, the toll must exceed the average value of time saved by the tolled as a result of the smoother flow of traffic. If differences in time valuation for tolled motorists are taken into account, only those with the highest values of time are made better off. Even those who had not been using the priced road before implementation of pricing (i.e., the "untolled," such as those using public transit or those driving on alternative routes) may be made worse off as a result of more crowded buses or roads made more congested by diverted traffic. The main beneficiary is the government, which benefits from the toll revenue.

\section{Improving the Public Acceptance of Fully-Priced Facilities}

The key to gaining public acceptability of any type of congestion pricing that involves tolling of existing free roads is the use of revenues. Small (1992) suggests that two-thirds of the revenue be given back to the motorist via commuter allowances, reduced road user taxes, and a reduction in general taxes. The other third would be used to pay for new road infrastructure, improvements in 
public transit, and in public services to business. Goodwin (1989) suggests that the revenue be arbitrarily divided such that a third would be used for new roadway infrastructure, a third would be allocated to improve public transport, and a third would be used to reduce the general tax burden or increase social spending.

This paper presents a direct approach for use of the revenues. It attempts to more directly "make whole" each of the three categories of travelers who are made worse off, i.e., the tolled, the tolled off, and the untolled. To benefit the tolled, it attempts to provide benefits commensurate with the value of tolls paid by providing significant travel time savings for them. This is accomplished by providing new highway capacity and advanced technologies that maintain the free flow of traffic and reduce the impact of incidents and accidents. To benefit the tolled off and the untolled, it enhances travel options, deploys new technologies for multimodal traveler information, and provides more effective traffic incident management and arterial traffic management.

The concept builds on emerging strategies implemented in Europe and now being explored by the transportation community in the United States as possible options for providing new highway capacity without the need for new rights-of-way or major reconstruction. However, the safety of these approaches has not yet been fully assessed in the U.S. context. Therefore, the concept proposed in this paper is not ready for immediate application. Rather, the intent is to engender discussion and further exploration through collaboration among the transportation planning, finance, safety, and operations communities to find workable strategies to advance the concept in the United States.

\section{FLEXIBLE AND EFFICIENT EXPRESS (FEE) HIGHWAYS}

\section{Providing Benefits for the Tolled}

In congested metropolitan areas, a new "dynamic" travel lane could be created on limited access highways by narrowing existing lanes and using shoulder space. The shoulder travel lane would be open for use by authorized vehicles with trained drivers in conjunction with active management of all lanes on the highway, using overhead lane controls and dynamic message signs to harmonize speeds and keep traffic flowing freely and safely (Figure 1). During peak periods, variable user fees would be used in conjunction with ramp metering to keep demand for use within the capacity of the reconfigured highway. Should an incident occur in any lane, surveillance cameras would automatically communicate with overhead lane controls, which would shut down the appropriate lane(s) in advance of the incident location.

User fee rates would be pre-scheduled according to time of day and location in order to manage demand based on observed traffic patterns. Dynamic pricing, which involves changing toll rates as often as every few minutes in response to real time traffic conditions, would not be used. This is because when an entire highway facility is priced, it is necessary to pre-schedule toll rates so that travelers can make rational travel choices before they begin their trips. To accomplish the same effect on flow as dynamic pricing, ramp metering would be used to fine tune traffic volume on the priced facilities by controlling access to the highway when demand is too close to capacity. This will ensure that traffic flow does not break down. Fees would be collected electronically at free-flow highway speeds using in-vehicle electronic tags. Vehicles without valid electronic tags would be identified and charged using license plate recognition technology. Buses and pre-registered vanpools would be issued special transponders that would exempt them from the fees.

Highway performance could be guaranteed to users. When an incident shuts down a lane or two, leading to congestion delays, all fees could be suspended since users would not get the level of service promised. The potential loss of revenue would provide an additional incentive to the highway operator to clear incidents quickly, and would reinforce the "fee for service" nature of the new charges in the minds of motorists.

This concept is termed "Flexible and Efficient Express" or FEE highways by the author, in order to reflect the "fee for service" aspect of this concept. It would require little or no new rights- 
Figure 1: Shoulder Travel Lane with Overhead Lane Controls in the Netherlands

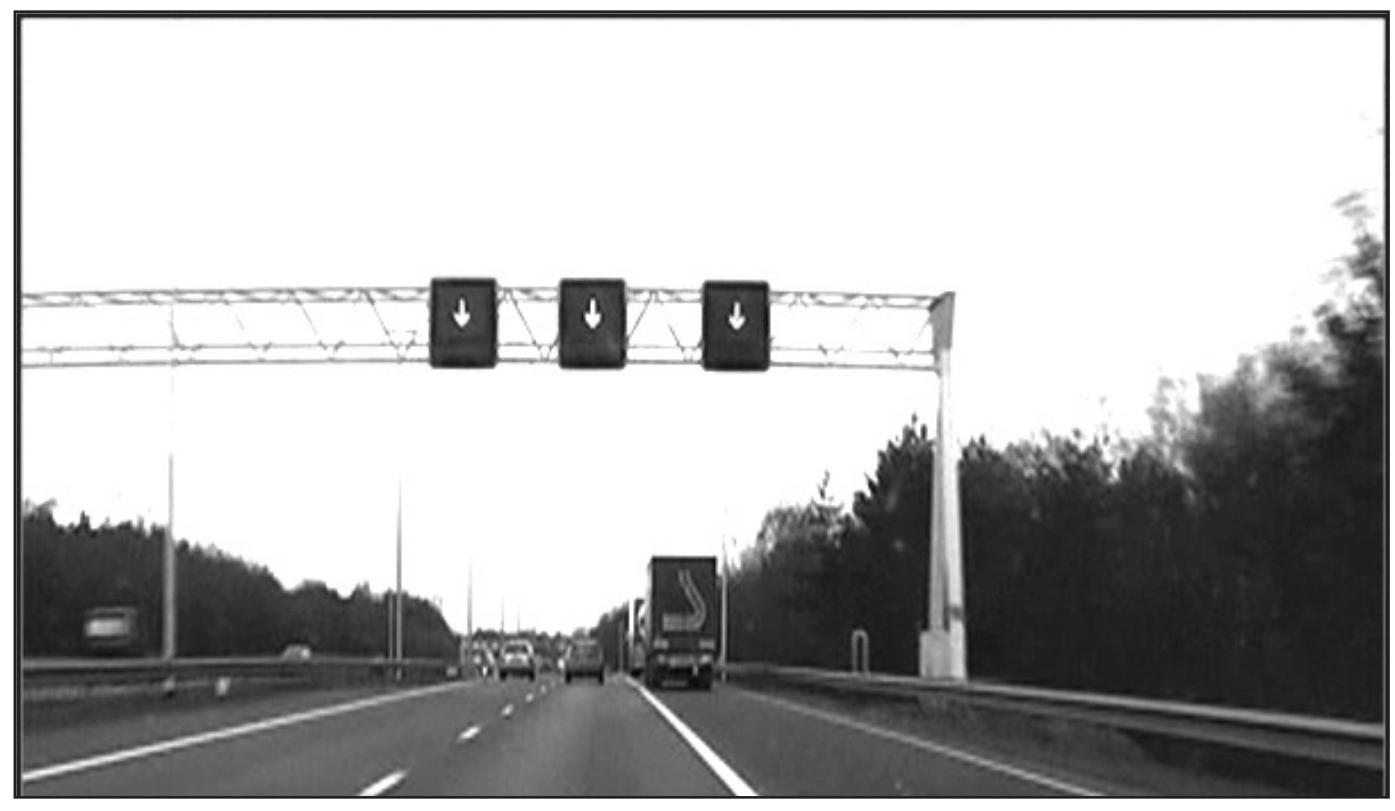

of-way, could be financed by leveraging the user fee revenue stream, and could be implemented in a relatively short period of time due to limited or no expansion of the highway footprint. Revenues from user fees could be used to pay for operations and maintenance, and for capital costs for shoulder improvements, new emergency pull-off areas, tolling infrastructure, active traffic management systems, enhanced transit and ridesharing services to provide viable alternatives to driving alone, and traffic flow improvements on alternative free routes.

In addition to alleviating recurring congestion, FEE highways could increase person throughput as well as vehicle throughput. Vehicle throughput would increase because an extra lane (i.e., the dynamic shoulder travel lane) would be available for use when needed. Also, demand management with pricing and ramp metering would prevent traffic flow breakdowns and thus eliminate the loss of vehicle throughput that currently occurs on unmanaged highways due to breakdown of traffic flow at bottlenecks (DeCorla-Souza 2010). Person throughput would increase due to increased use of transit and ridesharing.

Limited access highways with standard lanes and shoulders could be re-striped as follows to create FEE highways:

- Left shoulder with reduced width, if feasible;

- 11-foot-wide lanes, i.e., the lanes would be reduced from the standard 12-foot width, similar to narrowing of lanes in construction zones and on other urban facilities which accommodate heavy vehicles, albeit at lower speeds;

- A 13-foot-wide dynamic shoulder lane on the extreme right. (The wider lane is needed to allow for adequate lateral clearance between vehicles in the lane and any structures on the highway's edge.)

\section{Providing Benefits for the Tolled Off and the Untolled}

Since costs for highway expansion would be significantly reduced by the FEE highway concept and users of all lanes would be charged tolls, a significant surplus of revenues is anticipated. (An analysis to confirm this is presented later in the paper). The FEE concept would use surplus revenues for the benefit of the tolled off and the untolled by investing in complementary strategies as discussed below. 
Enhancement of travel choices. Bus Rapid Transit (BRT), express bus and bus priority systems (e.g., signal preemption) would create a "backbone" of fast and frequent transit service, supplemented with vanpooling, regular carpooling, and flexible carpooling. Flexible carpooling is similar to "slugging" as practiced in Northern Virginia, Houston, and the San Francisco Bay area, but with pre-certification of drivers and riders (Minett 2010a and 2010b). With flexible carpooling, potential carpoolers gather at designated locations and are picked up by a solo driver who seeks to qualify for use of HOV lanes or to avail himself or herself of HOV toll discounts or exemptions on priced facilities. This type of carpooling would supplement transit services and help reduce costs for operating peak period transit services while offering commuters an additional travel choice.

Flexible telecommuting. Incentives would be provided to employers to allow some of their employees to telecommute each morning until peak period tolls are no longer in effect and then drive in to work, or to leave work before peak tolls are in effect and then work from home.

Off-peak transit use incentives. If transit vehicles are too crowded in peak hours, some pressure could be relieved by off-peak or peak shoulder discounts or other incentives, such as the chance to win a lottery (Merugu, Prabhakar, and Rama 2009).

Technology. Pre-trip decisions on mode and time of travel could be made easier for the traveler by incorporating technologies for timely and reliable multimodal traveler information. Those who continue to drive could benefit from investment in technologies that provide traffic flow improvements, more effective traffic incident management, arterial and corridor management, and safety and mobility management in work zones.

\section{Implementation}

With so many different components and innovations, it will be difficult to implement the FEE highway concept all at once. Moreover, it is important to ensure that all strategies that are designed to provide better travel options are in place before actual congestion charging begins so that the public has time to become fully aware of the new options, and to ensure that they are all working effectively. Implementation of FEE highways might be pursued by corridor. The first step could be creation of shoulder travel lanes and use by transit and vanpool vehicles with trained drivers. This could be followed by opening up the lanes for use by carpools with three or more persons (with trained drivers) to provide a carpooling incentive. With these multimodal alternatives in place, the final step would be implementation of full pricing on all lanes along with multimodal traveler information systems and active traffic management.

Public-private partnerships (PPPs) could be used to increase the potential for innovation and on-time delivery. One type of PPP arrangement attempts to address the conflict between the private sector goal to maximize revenue and the public goal to maximize vehicle throughput. Under this method, termed "Concurrent Real and Shadow Tolling" (DeCorla-Souza 2006), the concessionaire would have freedom to set the toll rates needed to ensure free-flowing traffic during congested periods, but all "excess" charges above a benchmark flat toll rate (called a shadow toll) specified in the concession agreement would go the public authority. To maximize its shadow toll revenue, the private operator would need to maximize vehicle throughput, thus maximizing public goals.

\section{IMPACTS}

\section{Traffic Volumes, Speeds and Travel Times}

Table 2 presents results from a traffic impact analysis of the FEE highway concept for a 10-mile highway segment with six existing lanes (i.e., three per direction) reconfigured to four lanes per 
direction (i.e., total of eight lanes). For comparison, a "No Pricing" alternative with the same configuration was also analyzed, and the results are presented in Table 3.

The analysis was performed for a prototypical urban freeway that is severely congested, using procedures from the Highway Capacity Manual (Transportation Research Board 2000), i.e., the $\mathrm{HCM}$, and the following inputs and analytical procedures:

- The existing urban freeway is assumed to have standard 12-foot-wide lanes and a standard 10 -foot-wide right shoulder.

- Existing traffic demand is assumed to be at the maximum level that can be accommodated without breakdown of traffic flow (but at slow speeds), known as Level of Service E (LOS E). In reality, many segments of urban highways operate under breakdown flow conditions involving queuing. This is known as Level of Service F (LOS F). The LOS E traffic demand assumption provides a conservative estimate of benefits from pricing. For longterm analysis, a 5\% (total) secular growth is assumed in order to account for population and economic growth. This throws the facility into breakdown flow conditions, i.e., LOS F.

- To be conservative in estimating benefits, it is assumed that there will be no change in travel mode. An increase in transit and carpool use would increase person throughput on the FEE highway, and consequently the benefits.

- For the No Pricing alternative, induced and diverted traffic resulting from the increased capacity is estimated using elasticity of travel demand relative to travel time, rather than elasticity relative to total generalized cost of travel, because the other components of generalized cost perceived by motorists (i.e., vehicle operating cost and accident risk) will not change significantly as a result of capacity expansion. A short-term elasticity of demand relative to travel time of -0.28 and a long-term elasticity of -0.57 is used based on prior studies (DeCorla-Souza and Cohen 1997). Induced traffic is estimated in the column titled "GP Lanes (Initial)" in Table 3. A total of 984 vehicles per hour (vph) is induced, amounting to a $14 \%$ increase above the base case traffic volume of $6,930 \mathrm{vph}$.

- It is assumed that a minimum speed of $55 \mathrm{mph}$ is to be maintained on the FEE highway, and traffic volume on the highway is estimated on that basis. As indicated earlier, dynamic "real time" pricing is not needed because ramp metering would be used to hold at the entrance ramps any excess demand that threatens to reduce speeds below that threshold. Note that the FEE highway can accommodate more vehicles than in the base (six-lane) configuration due to the additional travel lane in each direction (see Table 2). However, the pricing mechanism curbs the higher level of induced travel seen in Table 3 when all lanes are unpriced. A small amount of induced traffic raises traffic volume to $7,069 \mathrm{vph}$, a $2 \%$ increase above the base case traffic volume of $6,930 \mathrm{vph}$.

- Free flow speeds for 12-foot lanes are estimated at $65 \mathrm{mph}$ based on Exhibit 13-6 of the HCM.

- Free flow speeds for 11-foot lanes are based on Exhibit 23-4 of the HCM; these speeds are further reduced due to reduced right shoulder lateral clearance, based on Exhibit 23-5 of the HCM. The resulting free flow speed is estimated at $60.7 \mathrm{mph}$.

- Actual operating speeds are estimated based on the Bureau of Public Roads (BPR) formula, with parameters from Nakamura and Kockelman (2002). The BPR formula and parameters used are explained in the footnotes of Table 2. Actual travel speeds are estimated at $46 \mathrm{mph}$ for No Pricing and $55 \mathrm{mph}$ for FEE highways.

Highway lane capacity is estimated as follows:

- For existing 12-foot-wide general purpose lanes, capacity is estimated at 2,350 vph, based on Exhibit 13-6 in the HCM.

- Base lane capacity for 11-foot-wide general purpose lanes is estimated as follows, based on Exhibit 23-3 of the HCM:

○ Capacity of 11 -foot-wide lane $=1,700+(10 \mathrm{x}$ Free flow speed $)=1,700+(10 \mathrm{x}$ $60.7)=2,307 \mathrm{vph}$. 
Table 2: Traffic Impacts on a 10-mile long 6-Lane Freeway Reconfigured into Four FEE Lanes per Direction

\begin{tabular}{lrr}
\hline & $\begin{array}{r}\text { Existing } \\
\text { Configuration }\end{array}$ & $\begin{array}{r}\text { Four FEE } \\
\text { Lanes }\end{array}$ \\
\cline { 2 - 3 } Traffic volume (demand) & 6,930 & 7,069 \\
Number of lanes per direction & 3 & 4 \\
Traffic volume per lane & 2,310 & 1,767 \\
Capacity per lane & 2,350 & 2,307 \\
Ratio of service flow volume at LOS C* to capacity & 0.65 & 0.65 \\
Service flow volume per lane at LOS C & 1,528 & 1,500 \\
Ratio of traffic volume to service flow volume at LOS C & 1.51 & 1.18 \\
BPR alpha ( $\alpha$ ) coefficient** & 0.02 & 0.02 \\
BPR beta ( $\beta$ ) coefficient** & 10 & 10 \\
Free flow speed (mph) & 65.00 & 60.70 \\
Travel time per mile with free flow speed (min.) & 0.92 & 0.99 \\
Actual travel time per mile (min.) & 2.08 & 1.09 \\
Time saved per mi. relative to Existing Configuration & & 0.99 \\
(minutes) & & 55.01 \\
Speed (mph) & 28.87 &
\end{tabular}

${ }^{*}$ LOS C $=$ Level of Service C. Engineers grade quality of service on roadway facilities at six levels, A through $\mathrm{F}$, with LOS A representing the best operating conditions and LOS F the worst. LOS C is considered an operating service level "acceptable" to users. LOS F represents conditions where traffic flow has broken down on a freeway.

** The Bureau of Public Roads (BPR) formula estimates travel time on a facility based on free-flow speed and the ratio of traffic volume to service flow volume at LOS C. Based on the BPR formula, actual travel time $=$ free-flow travel time $\mathrm{x}(1+\alpha \text { (ratio of traffic volume to service flow volume at LOS C) })^{\beta}$.

\section{Other Impacts}

Tables 4 and 5 present other impacts of the FEE highway and the No Pricing alternatives, respectively. Safety impacts have not been estimated. Since this is a prototypical analysis, user benefits (other than safety) are estimated using national average coefficients. For any specific urban area, coefficients and results would be different. The analytic procedures were as follows:

- Time savings. Time saved by induced and diverted travelers on free lanes for the No Pricing alternative is estimated at half the time saved by prior travelers on the free lanes, consistent with consumer surplus theory. Value of time saved is calculated based on the nationwide average value of time per vehicle hour from the Urban Mobility Report (Texas Transportation Institute 2007).

- Fuel cost savings. Fuel consumption savings due to reduced delays is estimated at 0.69 gallons per hour of delay saved based on the relationship between congestion delay and fuel consumption in Exhibit 1 of the 2007 Urban Mobility Report (Texas Transportation Institute 2007). Fuel cost is estimated at $\$ 2.50$ per gallon.

- Annualization of benefits. Congestion levels are assumed to prevail only during four hours per direction on each weekday, on 250 working weekdays per year. For example, the inbound direction of an urban radial freeway may be congested for three hours in the morning, but for only one hour in the afternoon, for a total of four hours each day.

- Toll Rates. Recall that FEE highways seek to ensure that the benefits (primarily travel time savings) to tolled vehicles are at least equal to the value of the toll paid, to ensure that 
Table 3: Traffic Impacts on a 10-mile 6-Lane Freeway Reconfigured to Four Free Lanes per Direction with No Pricing

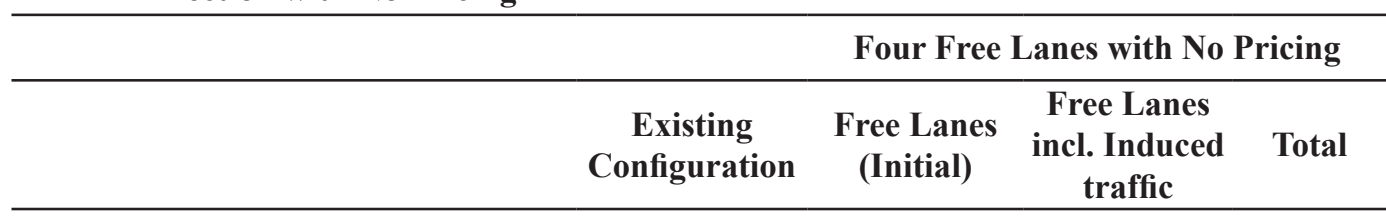

Traffic Impacts

Traffic volume (demand)

Number of lanes per direction

Traffic volume per lane

Capacity per lane

Ratio of service flow volume at LOS C to capacity

Service flow volume per lane at LOS C

Ratio of traffic volume to service flow volume at LOS C

BPR alpha coefficient

BPR beta coefficient

Free flow speed (mph)

Travel time per mile with free flow speed (minutes)

Actual travel time per mile (minutes)

Time saved per mi. relative to Existing

Configuration (minutes)

Speed (mph)

$$
6,930
$$

3

$$
2,310
$$

2,350

0.65

1,528

1.51

0.02

10

65.00

0.92

2.08

1.07

1.01

28.87

\section{Induced Travel Estimation}

Elasticity of demand relative to travel time

Initial VHT* at before expansion speeds

Initial VHT after facility expansion

Initial VHT savings

Delay VHT per additional VMT**

Induced travel
$-0.28$

240.02

123.84

116.17

0.05

984

$* \mathrm{VHT}=$ Vehicle hours of travel, i.e., travel time $\mathrm{x}$ traffic volume

$* * \mathrm{VMT}=$ Vehicle miles of travel, i.e., traffic volume $\mathrm{x}$ distance 
they are not made worse off with pricing. This means that the toll rate will be governed by the value of time of the tolled vehicle with the lowest value of time. This is used to estimate toll rates. Toll rates are estimated based on travel time saved by tolled vehicles (relative to the base case six-lane highway configuration), average value of time from the Urban Mobility Report (Texas Transportation Institute 2007), the distribution of the value of time of all freeway motorists under No Pricing (HDR Inc. 2009), and the percentage of vehicles that would be tolled off with pricing based on the difference between the total traffic on the highway with No Pricing from Table 3 (i.e., 7,914 vph) and the number of vehicles that can be accommodated on the FEE highway while meeting the $55 \mathrm{mph}$ speed target (i.e., 7,069 vph).

- Annual revenue. For annual revenue estimation, it is assumed that toll-exempt vehicles average 200 passenger car equivalents per hour per lane. Congestion levels (and the estimated fees) are assumed to apply only during four hours per direction on each weekday, on 250 working weekdays per year. However, revenue estimates based on these four hours are increased by $25 \%$ to account for revenues during shoulder hours. Tolling will be needed during shoulder hours to manage traffic that shifts from the peak hours to avoid the higher tolls during those hours.

- Greenhouse gas emissions. To estimate greenhouse gas emissions, it is assumed that $10 \%$ of total fuel consumed during peak periods is diesel fuel, and $90 \%$ is gasoline. The following relationships (HDR Inc. 2009) are used:

- Fuel efficiency (miles per gallon) is estimated based on speed, using the relationship: $8.8+0.25^{*}$ speed.

- $\mathrm{CO} 2$ emissions per gallon are estimated based on 8,788 grams per gallon of gasoline and 10,084 grams per gallon of diesel.

The results of the analyses for the two alternatives, for the first year after implementation, are presented in Tables 4 and 5 and summarized in Table 6 . The results suggest that in the first year the FEE highway alternative will provide much higher user benefits, i.e., almost $\$ 38$ million annually, vs. $\$ 31.25$ million for No Pricing. It will also result in more greenhouse gas reductions, i.e., a $28 \%$ reduction in peak period emissions, vs. a $10 \%$ reduction for No Pricing. Long-term analysis results, also presented in Table 6, show more striking differences. They show that as traffic demand increases and throws the facility into breakdown flow conditions, user benefits from FEE highways would be about twice the user benefits from No Pricing, i.e., \$66 million vs. \$33 million annually. In the long term, the No Pricing alternative will increase peak period greenhouse gas emissions by $7 \%$, vs. a $39 \%$ reduction for FEE highways. 
Table 4: Other Impacts on a 10-mile 6-Lane Freeway Reconfigured to Four FEE Lanes per Direction

\section{Existing \\ Configuration \\ Four FEE \\ Lanes}

\section{User Benefits on 10-mile Facility}

Facility length (mile)

10.00

10.00

Total travel time on facility per mile (min)

14,401

7,711

Total delay reduced per mile (minutes)

6,980

$\$ 14.60$

Average value of time (\$/hour)

$\$ 1,698.47$

Value of delay savings/mile/peak hour/direction

2

Number of directions

2

Peak hours per weekday for both directions

250

250

Value of delay savings per mile annually

Value of annual delay savings for full facility

$\$ \mathbf{\$ 3 3 , 9 6 9 , 3 4 5}$

Annual delay savings for 10-mile facility (hours)

$2,326,667$

Annual delay savings per 10-mile trip on the facility (hours)

Fuel cost per gallon

$\$ 2.50$

Gallons of fuel saved annually

$1,605,401$

Value of fuel saved

$\$ 4,013,501$

Total delay and fuel cost saved annually

$\$ 37,982,846$

\section{Toll Revenue on 10-mile Facility}

Travel time saved in priced lanes $(\mathrm{min} / \mathrm{mi})$

0.99

Percent of traffic volume reduction relative to No Pricing

$-12 \%$

Percentile in WTP distribution

$12 \%$

$\$ 0.10$

Average toll rate per mile

$\$ 0.97$

Average toll for 10-mile trip

200

No. of exempt vehicles/hour (passenger car equivalents)

Factor to account for revenue during shoulder hours

$\$ 16,593,749$

\section{Greenhouse gas emissions on 10-mile Facility}

Fuel consumption rate (mpg)

Annual fuel consumption (gallons)

$\mathrm{CO} 2$ emissions per gallon 
Table 5: Other Impacts on a 10-mile 6-Lane Freeway Reconfigured into Four Free Lanes with No Pricing

\begin{tabular}{|c|c|c|}
\hline & $\begin{array}{c}\text { Existing } \\
\text { Configuration }\end{array}$ & $\begin{array}{c}\text { Four Free } \\
\text { Lanes with } \\
\text { No Pricing }\end{array}$ \\
\hline \multicolumn{3}{|l|}{ User Benefits on 10-mile Facility } \\
\hline Facility length (mile) & 10.00 & 10.00 \\
\hline Total travel time on facility per mile (min) & 14,401 & 10,323 \\
\hline Total delay reduced per mile (minutes) & & 5,742 \\
\hline Average value of time (\$/hour) & & $\$ 14.60$ \\
\hline Value of delay savings/mile/peak hour/direction & & $\$ 1,397.18$ \\
\hline Number of directions & 2 & 2 \\
\hline Peak hours per weekday for both directions & 4 & 4 \\
\hline Number of weekdays per year & 250 & 250 \\
\hline Value of delay savings per mile annually & & $\$ 2,794,363$ \\
\hline Value of annual delay savings for full facility & & $\$ 27,943,633$ \\
\hline Annual delay savings for 10-mile facility (hours) & & $1,913,947$ \\
\hline Annual delay savings per 10-mile trip on the facility hours) & & 30 \\
\hline Fuel cost per gallon & & $\$ 2.50$ \\
\hline Gallons of fuel saved annually & & $1,320,624$ \\
\hline Value of fuel saved & & $\$ 3,301,559$ \\
\hline Total delay and fuel cost saved annually & & $\$ 31,245,192$ \\
\hline \multicolumn{3}{|l|}{ Greenhouse gas emissions on 10 -mile Facility } \\
\hline Fuel consumption rate (mpg) & 16 & 20 \\
\hline Annual fuel consumption (gallons) & $8,652,619$ & $7,797,092$ \\
\hline $\mathrm{CO} 2$ emissions per gallon & 8,918 & 8,918 \\
\hline $\mathrm{CO} 2$ emissions annually (metric tons) & 77,161 & 69,531 \\
\hline Percent change with four Free Lanes & & $-10 \%$ \\
\hline
\end{tabular}


Table 6: Summary of Short-Term and Long-Term Impacts of Alternative Reconfigurations of a 10-Mile Six-Lane Freeway

\section{Short-Term}

User Benefits

Annual delay reduced per 10-mile trip (hrs.)

Annual value of user benefits (\$millions)

\section{Revenues}

Charge for 10-mile trip (\$)

Annual revenues (\$millions)

\section{Sustainability}

Change in peak period $\mathrm{CO} 2$ emissions (\%)

\section{Four FEE}

Lanes

41

$\$ 37.98$

$\$ 0.97$

$\$ 16.59$

$-28 \%$

41

\section{No Pricing}

$\$ 31.25$

$\$ 0.00$

$\$ 0.00$

\section{Long-Term}

\section{User Benefits}

Annual delay reduced per 10-mile trip (hrs.)

Annual value of user benefits (\$millions)

\section{Revenues}

Charge for 10-mile trip (\$)

Annual revenues (\$millions)

\section{Sustainability}

Change in peak period $\mathrm{CO} 2$ emissions (\%)

$-39 \%$

\section{REGIONWIDE APPLICATION OF THE FEE HIGHWAY CONCEPT}

A typical large metropolitan area such as Seattle, WA, or Washington, DC, has a freeway network of about 300 miles or 1,800 lane miles. Table 7 shows results from an extrapolation of the impacts estimated for a 10-mile highway to a 300-mile highway network. Preliminary cost estimates for conversion of standard highways to FEE highways, including tolling and active traffic management, have been prepared for a study in progress by Booz Allen Hamilton for the Federal Highway Administration. Based on this study, annualized capital and operating costs (in real dollars) are estimated at about $\$ 500$ million for the No Pricing alternative and $\$ 610$ million for the FEE highway alternative.

Estimated user benefits, shown in Table 7, for both alternatives exceed these costs by $87 \%$ in the first year (short term), but benefits increase by significant amounts in the long term with growth in demand. User benefits in the long term are almost $\$ 2$ billion annually for FEE highways, resulting in a benefit-cost ratio of 3.24. For No Pricing, the comparable user benefits are over $\$ 1$ billion, resulting in a benefit-cost ratio exceeding 2.02 .

Table 7 suggests that, for a 300-mile congested network, the FEE highway concept could generate almost $\$ 0.5$ billion in toll revenue in the first year after implementation. In the longer term, annual revenues could be as much as $\$ 1$ billion annually. All revenue estimates are in real dollars, and the long-term revenue estimates are conservative because the value of time parameter was not adjusted to account for the increases in real wage rates that can be expected over time. The No Pricing alternative generates no toll revenue. Revenues for the 300-mile FEE highway network concept fall short of costs in the first year by about $\$ 110$ million (i.e., $\$ 610$ million in costs vs. about $\$ 0.5$ billion in toll revenue), but estimated long-term revenues are more than adequate to cover the annualized costs, generating over $\$ 400$ million in toll revenue surpluses annually (i.e., $\$ 610$ million 
in costs vs. about $\$ 1.01$ billion in revenue). The stream of surpluses could be leveraged to fund multimodal transportation investments and other strategies to benefit the tolled off and the untolled.

Table 7: Summary of Short-Term and Long-Term Impacts of Alternative Reconfigurations of a Regional Network of Freeways

$\begin{array}{lrr} & \text { Four FEE } & \\ \text { Short-Term } & \text { Lanes } & \text { No Pricing } \\ \text { Number of miles of freeway (avg. 6 lanes) } & 300 & 300 \\ \text { Annual value of user benefits (\$millions) } & \$ 1,139 & \$ 937 \\ \text { Annual revenues (\$millions) } & \$ 498 & \$ 0 \\ \text { Annual costs (\$millions) } & \$ 610 & \$ 500 \\ \text { Benefit/cost ratio } & 1.87 & 1.87 \\ \text { Annual surplus (+) or deficit (-) } & (\$ 112.19) & (\$ 500.00) \\ & & \\ \text { Long-Term } & & 300 \\ \text { Number of miles of freeway (avg. 6 lanes) } & 300 & \$ 1,010 \\ \text { Annual value of user benefits (\$millions) } & \$ 1,978 & \$ 0 \\ \text { Annual revenues (\$millions) } & \$ 1,013 & \$ 500 \\ \text { Annual costs (\$millions) } & \$ 610 & 2.02 \\ \text { Benefit/cost ratio } & 3.24 & (\$ 500.00) \\ \text { Annual surplus (+) or deficit (-) }\end{array}$

\section{ADDRESSING THE ISSUES}

\section{Safety}

A summary of research on the safety impacts of narrower lanes is provided by $\mathrm{Ng}$ and Small (2009). The authors find that both theoretical and empirical evidence linking narrow lane design to safety are ambiguous. According to the authors, it is an open question whether narrow lanes would in fact reduce safety. They suggest that it would depend on factors that vary from case to case, especially the speeds chosen by drivers. They cite several innovations in Europe that offer hope that roads designed for lower speeds could be accompanied by measures to ensure that lower speeds in fact prevail. For example, they point out that variable speed limits have been used for many years in Germany and the Netherlands, and recently in Copenhagen, primarily to smooth traffic during the onset of congestion - but also with a strong reduction in injury accidents in one German implementation.

A study by the Midwest Research Institute (Bauer et al. 2004) suggests that the observed increases in accident frequency when freeways in the United States have been re-striped to narrower lanes cannot necessarily be attributed to the use of narrower lanes or the conversion of a shoulder to a travel lane. The authors suggest that the use of the added narrow lanes as HOV lanes introduces a difference in speed between adjacent lanes, which may be another explanation for the increase in accidents. The FEE highway concept eliminates these speed differentials, since vehicles in all lanes travel at essentially the same free-flow speed when all lanes are priced.

Nonetheless, the use of shoulders as travel lanes does present safety challenges, which need to be addressed. For example, protocols will need to be developed for emergency response when the shoulder is being used as a travel lane. The first project in the United States to use a shoulder as travel lane "dynamically" during peak periods was implemented on I-35W in Minneapolis in October 2009, and the United States will learn from that experiment. 


\section{Impacts on Alternative Free Routes}

The FEE highway's capacity will be higher than the existing highway's capacity, due to the extra FEE lane. If the FEE highway were available for use free of charge during peak periods, it could be expected that some drivers who currently drive on parallel facilities to avoid congestion on the highway would shift to the FEE highway, reducing traffic on the parallel facilities. Peak period fees charged on the FEE highway will need to be high enough to keep excessive traffic away and maintain free flow of traffic on the expanded capacity. However, fees must also be low enough to ensure that the FEE highway is fully utilized. This will ensure that net diversion to alternative free routes does not occur.

Some drivers who do not value their time very highly (and have low willingness to pay) are likely to shift to free parallel surface facilities. However, this shift in traffic to free facilities is likely to be counterbalanced by shifts in traffic from free facilities to the FEE highway by those who value the time savings more highly than the fees charged on the FEE highway.

A redistribution of traffic will occur based on driver values of time, but not necessarily a significant increase in traffic either on the FEE highway or on parallel free facilities. Only drivers who have very low values of time will be tolled off. This does pose an equity issue with regard to low-income drivers, and is discussed later in this paper (see Public Acceptance Issues).

\section{Overall Congestion Reduction Impacts}

In a typical large city, VMT on limited access highways tends to exceed VMT on arterials. For example, Seattle's 2007 daily VMT on limited access highways was 30.6 million, vs. only 27.1 million for arterials (Texas Transportation Institute 2009). However, a major portion of the delay faced by travelers tends to be on limited access highways, so FEE highways could alleviate a majority of the recurring congestion delay in metropolitan areas.

The advantage of limiting pricing to limited access highways is that it can be implemented in the short term using existing proven transponder-based technologies which are already widely deployed in the United States. Recent research under the National Cooperative Highway Research Program (Sorenson et al. 2009) explored other technology that could potentially be used to collect ubiquitous user charges. When they are further developed and deployed in the future, they could potentially be used to complement the FEE highway concept by deploying pricing on roads off the FEE highway system.

\section{Public Concerns About Fairness}

Imposing new charges on existing toll-free roads raises fairness concerns. Many people believe they have already paid for existing roads with their taxes, and new charges would amount to double taxation. However, experience shows that if the public understands the high costs for reconstruction, rehabilitation, and expansion of highway facilities, they may accept congestion pricing as one way to help pay for these costs while receiving improved mobility from congestion relief. The SR 520 floating bridge in the Seattle metropolitan area will become the first existing toll-free facility in the United States to charge new tolls that will vary by time of day to achieve performance targets. The public in Seattle understands the high costs to replace the SR 520 bridge, and that tax dollars will be insufficient to pay for these costs.

Public opinion surveys suggest that the public is more accepting of new charges if they are convinced that revenues from new charges will go directly towards providing improved transportation service on the facilities on which the charges are imposed. The public accepts toll roads because they can see that the revenues go to support the specific facility on which they pay tolls (Zmud and Arce 2008). 
The public will need to understand that tolls would only be charged during peak hours with FEE highways - unlike regular toll roads. If road users understand that FEE highways are not regular toll roads, they could be convinced that the new charges will be a just and fair "fee for service" that goes to provide improved peak period service made possible by the extra physical capacity being provided. In South Africa's Johannesburg/Pretoria metropolitan area, 115 route miles of existing freeway are being widened and an additional 236 route miles are being upgraded, all of which will be funded through new electronically charged tolls on the existing free system (Poole 2009). This demonstrates that concerns about "double taxation" can be alleviated when the new charges are directly related to the extra benefits being provided.

\section{Concerns About Equity for Low-Income Drivers}

Due to the increase in capacity with FEE highways, few motorists (if any) would need to be "tolled off" - so tolls would be relatively low and quite affordable. Like vehicle property taxes in some states, tolling could be made more progressive by charging toll rates that vary based on value of the vehicle being tolled. Yet valid concerns may be expressed that the new fees may make it too expensive for low-skilled workers to get to their jobs, because low-skilled jobs are often not well served by public transit. Also, low-income workers tend to have jobs with fixed schedules, and pricing may be particularly unfair to those with less flexible work schedules since they are unable to shift their time of travel.

A well-designed FEE highway pricing strategy can be less burdensome to low-income citizens with appropriate use of toll revenue. With a portion of the toll revenue dedicated to transit, lowincome transit riders can benefit significantly from toll-financed transit improvements. Policymakers can also include protections for low-income individuals, such as "life-line" credits or toll discounts, or reimbursements for tolls paid. For example, a proposal for congestion pricing in New York City by its mayor in 2008 would have provided reimbursements to low-income individuals qualifying for the federal earned income credit. They would be reimbursed for any charges in excess of the fare for a transit trip.

\section{Concerns About Administrative Costs}

Concerns are often expressed about the high administrative costs for implementing and operating a congestion pricing scheme relative to other ways of generating revenue from highway users. Operating costs amount to about $20 \%$ of revenue for a normal toll facility, based on a study in progress for the National Cooperative Highway Research Program (NCHRP project 19-08). By comparison, collection of fuel taxes costs only about $1 \%$ of revenue.

Yet congestion pricing may be justified despite the high costs, because costs for implementation and operation are significantly exceeded by the benefits. The purpose of congestion pricing is not simply to collect revenue, but also to achieve other economic, social, and environmental goals. If the same amount of revenue as generated from congestion pricing were instead to be raised by fuel taxes, costs for revenue collection would indeed be lower, but the loss of benefits would be far greater than the cost savings. For decision making, the costs for implementation and operation of FEE highways must be compared with benefits, not with revenues collected. As Table 7 shows, the value of incremental user benefits alone (i.e., time and fuel cost savings) would far exceed incremental costs for implementation and operation of FEE highways relative to the No Pricing alternative. Long-term incremental user benefits for a 300-mile FEE highway network relative to a No Pricing network with the same configuration are almost $\$ 1$ billion annually (i.e., $\$ 1.9$ billion minus $\$ 1.0$ billion), vs. incremental costs of only $\$ 110$ million annually (i.e., $\$ 610$ million minus $\$ 500$ million).

Synergistic combinations of FEE highways and supporting strategies should be subjected to a comparative benefit-cost or cost-effectiveness evaluation and compared with other traditionally 
funded alternatives. The long-range transportation planning process undertaken by metropolitan planning organizations (MPOs) could be used to inform the public about costs and benefits of alternative approaches. This would begin a discussion about the tradeoffs between conventional transportation investment approaches and approaches involving congestion pricing. The MPO in Seattle is showing the way in the United States. Five synergistic pricing alternatives were recently analyzed and presented for consideration by the public for the Year 2040 Regional Transportation Plan for the Seattle area (Puget Sound Regional Council 2009). This led to adoption by policymakers of a fully-priced highway network as part of the Year 2040 Regional Transportation Plan in May 2010 .

\section{Concerns About Privacy}

Proposals to price the entire network of highways and surface streets using global positioning systems (GPS) have raised significant privacy concerns. Even if the detailed information on travel never leaves the vehicle (as proposed with some concepts), there is a concern that information stored electronically on in-vehicle units is insecure and may become available to unauthorized persons. However, privacy does not appear to be a major concern with pricing of only the limited access highway network using transponder-based toll collection technology as envisioned for FEE highways. In a focus group study on such a strategy (Petrella, Biernbaum, and Lappin 2008), privacy was not an issue that resonated strongly or generated much discussion with most participants, perhaps because vehicle identification technology would be restricted to limited access highways only, and information on trip origins and destinations off the tolled system would not be collected.

All operating HOT lane projects in the United States and more than 250 other toll facilities across the country use electronic toll collection (ETC). Yet, some people continue to be concerned about the privacy impacts of ETC. In response, tolling agencies have devised a method to protect the public's privacy by linking the transponder and the driver's personal information with a generic, internal account number that does not reveal the driver's identity and that is not disclosed to other organizations. In many cases, a motorist can open an anonymous pre-paid account if he or she so chooses, although there have been very few who have signed up. Singapore has alleviated privacy concerns by collecting tolls using smart cards with stored value that are inserted into an in-vehicle unit. These "electronic purses" are replenishable at Automated Teller Machines (ATMs), and may also be used for other purchases unrelated to tolling. However, the in-vehicle units needed for such systems are far more expensive than the typical transponders used in the United States.

\section{SUMMARY AND CONCLUSIONS}

A sketch-level analysis of the FEE highway concept presented in this paper suggests that it could prove to be a financially feasible way to create a high-performance metropolitan transportation system. However, more detailed assessments of the opportunities and options in specific metropolitan areas will be needed, and safety challenges will need to be addressed. The intent of this paper is to stimulate further exploration and discussion of the concept and to generate other ideas.

\section{References}

Bauer, Karin M., Douglas W. Harwood, Warren E. Hughes, and Karen R. Richard. "Safety Effects of Narrow Lanes and Shoulder-Use Lanes to Increase Capacity of Urban Freeways." Transportation Research Record 1897. Transportation Research Board, National Research Council, (2004): 71-80.

DeCorla-Souza, Patrick and Harry Cohen. "Accounting for Induced Travel in Evaluation of Urban Highway Expansion.” Transportation 24(2), (1997): 107-123. Http://www.fhwa.dot.gov/steam/ doc.htm. 
DeCorla-Souza, Patrick. "Implementing Congestion Pricing on Metropolitan Highway Networks with Self-Financing Public-Private Partnerships." Journal of the Transportation Research Forum 45(1), (2006): 5-22.

DeCorla-Souza, Patrick. "A Freeway Congestion Pricing Paradox." Presented at the Transportation Research Board Annual Meeting, Washington, D.C., 2010.

Dupuit, J. "On the Measurement of the Utility of Public Works." Annales des Ponts et Chaussses, $2^{\text {nd }}$ series, 8, 1844, reprinted in Transport, edited by D. Munby, (1968): 19-57.

Federal Highway Administration. 2006 Status of the Nation's Highways, Bridges, and Transit: Conditions and Performance. Appendix A: Highway Investment Analysis Methodology. HERS Highway Improvement Cost Inputs, 2007. Http://www.fhwa.dot.gov/policy/2006cpr/appa.htm.

Federal Highway Administration. Current Toll Road Activity in the U.S.: A Survey and Analysis, 2009. Http://www.fhwa.dot.gov/ipd/pdfs/2008_toll_activity_white_paper.pdf.

Goodwin, P. "The Rule of Three: A Possible Solution to the Political Problem of Competing Objectives for Road Pricing." Transport Engineering and Control 30, (1989): 495-497.

Hau, Timothy. "Economic Fundamentals of Road Pricing: A Diagrammatic Analysis, Part 1 Fundamentals." Transportmetrica 1(2), (2005): 81-117.

HDR, Inc. TRUCE-ST User's Guide. Prepared for the Federal Highway Administration, 2009. Http://ops.fhwa.dot.gov/tolling_pricing/value_pricing/tools/index.htm.

Knight, F. H. "Some Fallacies in the Interpretation of Social Cost." Quarterly Journal of Economics 38, (1924): 582-606.

Lee, Douglass B., Jr. "Toward the Evaluation of Value Pricing." Transportation Research Record No. 2079, Transportation Research Board, (2008): 71-88.

Merugu, Deepak, Balaji S. Prabhakar, and N.S. Rama. "An Incentive Mechanism for Decongesting the Roads: A Pilot Program in Bangalore.” Http:/netecon.seas.harvard.edu/NetEcon09/Papers/ Merugu_09.pdf.

Minett, Paul. "Enabling a Flexible Ridesharing Response to Congestion Pricing." Presentation at the Innovations in Pricing of Transportation Systems Conference \& Workshop, Orlando, Florida, May 2010a. Http://www.flexiblecarpooling.org /fcdecongestionpricing.pdf.

Minett, Paul. "Not Only Seeing, But Also Knowing Who is in the HOV." Presentation at the Innovations in Pricing of Transportation Systems Conference \& Workshop, Orlando, Florida, May 2010b. Http://www.flexiblecarpooling.org/fcdecongestionpricingtechnology.pdf.

Ministry of Transport. Road Pricing: the Economic and Technical Possibilities (the Smeed Report), 1964.

Nakamura, K. and K. Kockelman. "Congestion Pricing and Roadspace Rationing: An Application to the San Francisco Bay Bridge Corridor.” Transportation Research 36A (5), (2002): 403-417.

$\mathrm{Ng}$, Chen Feng and Kenneth Small. "Tradeoffs Among Free-flow Speed, Capacity, Cost, and Environmental Footprint in Highway Design, 2009.” Http://www.economics.uci.edu/docs/2008-09/ small-04.pdf. 
Petrella, Margaret, Lee Biernbaum, and Jane Lappin. "Exploring a New Congestion Pricing Concept: Focus Group Findings from Northern Virginia and Philadelphia." Volpe National Transportation Systems Center, Cambridge, Massachusetts, 2008. Http://ops.fhwa.dot.gov/tolling pricing/resources/report/cpcfocusgrp/congestion_focus_grp.pdf.

Pigou, A. The Economics of Welfare. Macmillan, London, 1920.

Poole, Robert. "Surface Transportation Innovations." Reason Foundation. Issue No. 74, Los Angeles, California, 2009.

Puget Sound Regional Council. "Transportation 2040: Draft Environmental Impact Statement, 2009.” Http://psrc.org/projects/trans2040/deis/index.htm.

Small, K. "Using the Revenues from Congestion Pricing." Transportation 19, (1992): 359-381.

Sorensen, Paul, Liisa Ecola, Martin Wachs, Max Donath, Lee Munnich, and Betty Serian. National Cooperative Highway Research Program (NCHRP) Web-Only Document 143: "Implementable Strategies for Shifting to Direct Usage-Based Charges for Transportation Funding." Transportation Research Board, Washington, D.C., 2009.

Texas Transportation Institute. 2007 Urban Mobility Report: Appendix A. Texas A \& M University, College Station, Texas, 2007.

Texas Transportation Institute. 2009 Urban Mobility Report. Texas A \& M University, College Station, Texas, 2009. Http://mobility.tamu.edu/ums/congestion_data/tables /seattle.pdf.

Transportation Research Board. Highway Capacity Manual. National Research Council, Washington, D.C., 2000.

Vickrey, W. S. “Congestion Charges and Welfare: Some Answers to Sharp's Doubts.” Journal of Transport Economics and Policy 95, (1968):107-118.

Walters, A. A. "The Theory and Measurement of Private and Social Cost of Highway Congestion." Econometrica 29, (1961): 676-699.

Zmud, Johanna and Carlos Arce. "Compilation of Public Opinion Data on Tolls and Road Pricing." NCHRP Synthesis 377. Transportation Research Board, 2008. Http://onlinepubs.trb.org/onlinepubs/ nchrp/nchrp_syn_377.pdf.

Patrick DeCorla-Souza is the Tolling and Pricing Program manager at the U.S. Department of Transportation's Federal Highway Administration. In this role, Patrick coordinates and oversees road pricing research and initiatives across the United States, and works with public and private sector partners nationwide to implement innovative road pricing strategies. Patrick has master's degrees in transportation planning and civil engineering, and co-chairs the Transportation Research Board's Congestion Pricing Committee. 